\title{
USO DE ANTICUERPOS MONOCLONALES PARA CARACTERIZAR TUMORES LINFOIDES AVIARES
}

\author{
Richard Tasayco A. ${ }^{1}$, Raúl Rosadio A. ${ }^{2,3}$, Eliana Icochea D’A. ${ }^{4}$ y Hermelinda Rivera G. ${ }^{2}$
}

\section{Abstract}

Macroscopic and histological tests were compared with presence of cell marker tests to better differentiate between Marek's Disease (MD) and Lymphoid Leukosis (LL) to improve the diagnosis criteria on avian lymphoid tumors. These tests were carried out on 40 laying hens affected with tumors from commercial farms on the North coast of Peru (Trujillo, Lima and Chincha). Initially, using macroscopic criteria (age and affected organ) it was determined that $60 \%(\mathrm{n}=24)$ were affected from MD and the other $40 \%(\mathrm{n}=16)$ from LL. Subsequently, presence of infiltrated pleomorphyc lymphocytes in histopathological tests (HP), was a criteria used to determine that $45 \%(\mathrm{n}=18)$ of the tumors were caused by MD and the other 22 had histological characteristics corresponding to LL (presence of homogeneous lymphoblasts forming nodules). In this way, the direct immunofluorescence test (IF) using monoclonal antibodies (MoAb) that was developed to identify lymphocyte T markers (CD3+), confirmed that only 50\% (9/18) of the animals histologicaly diagnosed with MD had transformed T cells. Similarly, the MoAb for lymphocyte B (Ig M+), detected that only $54.6 \%$ (12/22) had transformed cells corresponding to lymphocyte B. Surprisingly, in 12/40 hens with nodular lymphoid tumors neither cell T nor cell B markers could be identified and in $9 / 40$ cell markers for both kinds of cell ( $T$ and $B$ ) were able to be identified in the tumors. Also, in 3/18 and 2/22 of the samples diagnosed histopathologicaly with $\mathrm{MD}$ and LL respectively, the presence for myelocites was found suggesting the presence of avian leukosis virus subgroup J. Kappa and McNemar statistic tests showed that for Marek's Disease had low concordance between HP and IF (-0.045); however, both methods (HP and IF) had a reasonable rate of concordance (0.314) for lymphoid leukosis. It is, concluded that the immunofluorescence test using the cell markers detection for monoclonal antibodies allows a more exact and efficient differential diagnosis than the histopathological test on avian lymphoid tumors. However, the histopathological and the immunofluorescence test are not mutually replaceable.

Key words: Marek's disease, lymphoid leukosis, lymphoid tumors, immunofluorescence test

\section{RESUMEN}

Con el objetivo de mejorar los criterios diagnósticos en tumores linfoides aviares, se compararon exámenes macroscópicos, histopatológicos y presencia de marcadores celulares para diferenciar enfermedad de Marek (EM) y leucosis linfoide (LL). Se utilizaron 40 gallinas ponedoras afectadas por tumores, procedentes de granjas comerciales de la costa del Perú (Trujillo, Lima y Chincha). Inicialmente, utilizando criterios macroscópicos

\footnotetext{
${ }^{1}$ Facultad de Agronomía, Universidad Hermilio Valdizán, Huánuco

${ }^{2}$ Laboratorio de Microbiología y Parasitología Veterinaria, FMV-UNMSM

3 rrosadio@terra.com.pe

${ }^{4}$ Laboratorio de Patología Aviar y Producción Avícola, FMV-UNMSM
} 
(edad y órganos afectados), se determinó que el 60\% (n=24) padecían de EM y las 16 restantes de LL. Posteriormente, la presencia de linfocitos infiltrantes pleomórficos en exámenes histopatológicos (HP) en estas mismas aves, fue usado como criterio para diagnosticar que el $45 \%(n=18)$ correspondían a EM y las 22 restantes tenían características histológicas correspondientes a LL (presencia de linfoblastos homogéneos formando nódulos). La prueba de inmunofluorescencia (IF) directa y utilizando anticuerpos monoclonales (AcMo) desarrollados para identificar marcadores de linfocitos $\mathrm{T}(\mathrm{CD} 3+)$, confirmó que solamente el 50\% (9/18) de animales histológicamente diagnosticados como EM, contenían células T transformadas. Similarmente, el AcMo para linfocitos B (Ig M+) detectó que solamente el $54.6 \%$ (12/22) tenían células transformadas correspondientes a linfocitos B. Sorprendentemente, en 12/40 (30\%) de las aves con tumores linfoides, no se logró identificar marcadores de células T ni de B y en 9/40 se logró identificar marcadores de ambas células (T y B) en los tumores. Por otro lado, en 3/18 y 2/22 de las muestras diagnosticadas histopatológicamente como EM y LL, respectivamente, microscópicamente se encontró, además, la presencia de mielocitos, sugiriendo la presencia del virus de leucosis aviar tipo J. Las pruebas estadísticas de Kappa y Mc Nemar mostraron que para la enfermedad de Marek, la concordancia es baja entre HP e IF (0.045); sin embargo, para leucosis linfoide, ambos métodos (HP e IF) presentan un índice regular de concordancia (0.314). Finalmente, se concluye que la inmunofluorescencia mediante la detección de marcadores celulares, usando anticuerpos monoclonales, permite un diagnóstico diferencial más preciso y es más eficiente que el examen histopatológico en tumores linfoides aviares; sin embargo, el examen histopatológico y la inmunofluorescencia no son mutuamente reemplazables.

Palabras clave: Enfermedad de Marek, leucosis linfoide, tumores linfoides, prueba de inmunofluorescencia

\section{INTRODUCCIÓN}

Los tumores linfoides o linfomas son las enfermedades neoplásicas más comunes de las aves. Estos tumores son producto de infecciones virales, generalmente por herpesvirus y retrovirus. El virus de la enfermedad de Marek (MDV), miembro de la familia Herpesviridae, produce linfomas usualmente en linfocitos T. Las infecciones retrovirales que se describen en aves son producidos por los denominados virus exógenos agrupados como retrovirus de la leucosis aviar (ALV). Estos retrovirus producen una gama de tumores de origen linfocitario de células B (leucosis linfoide), eritroideo (eritroblastosis) y mieloide (mieloblastosis y mielocitomatosis), pudiendo además ocasionar infiltraciones tumorales en una variedad de tejidos parenquimatosos (tumores sólidos). Por otro lado, se describe al retrovirus de la retículoendoteliosis
(REV) con capacidad de causar linfoma de células B en pollos y células T en otras especies de aves (Payne y Mc Kay, 1999).

En el diagnóstico diferencial de los tumores linfoides en aves se utilizan varios criterios que incluyen el clínico y las alteraciones macro y/o microscópicas, y, usualmente, se busca diferenciar las infecciones aviares más prevalentes, como la enfermedad de Marek (EM) y la leucosis linfoide (LL). Entre las infecciones herpéticas, la enfermedad de Marek (EM) es la más común de las enfermedades linfoproliferativas de pollos, y se caracteriza por infiltraciones de células mononucleares en nervios periféricos y/o gónadas, iris, hígado, bazo, corazón, riñones, proventrículo, pulmón, mesenterio, bursa, timo, glándula adrenal, páncreas, intestino, músculos y piel (Calnek y Witter, 1997). Estas infiltraciones producen signos clínicos en pollos que muchas veces, con la excepción 
del compromiso neural, son de poca ayuda para establecer un diagnóstico diferencial adecuado (Calnek y Witter, 1997; Muñoz, 2000). Las lesiones neoplásicas viscerales macroscópicas observadas en animales infectados por la EM son indistinguibles de las lesiones leucósicas inducidas por infecciones retrovirales.

El término de leucosis o sarcoma aviar es utilizado para describir a una variedad de neoplasias transmisibles en aves que son producto de infecciones retrovirales. La leucosis linfoide es la forma más común de este grupo y la más devastadora en las explotaciones avícolas a nivel mundial. Los tumores en esta enfermedad comprometen la bursa, hígado, bazo y otros órganos viscerales con cambios macroscópicos que muchas veces no son fácilmente distinguibles de las ocasionadas por infecciones herpéticas. El diagnóstico diferencial de los tumores linfoides aviares se ha complicado por los tumores de origen mieloide (mielocitomatosis y/o mieloblastosis). Macroscópicamente, las células mieloides transformadas tienden a involucrar a la superficie de los huesos y una variedad de órganos viscerales que ayudan a diferenciarlas de otros tipos de tumores, pero estos tipos de tumores tienden a coexistir con otras infecciones virales (Spencer, 1998).

Los tumores asociados a infecciones por el virus de la leucosis aviar son blandos, lisos y brillosos. Al corte son de color ligeramente gris a blanco acuoso con áreas de necrosis. El crecimiento puede ser nodular, miliar, difuso o combinado. En la forma nodular varían de 0.5 a $5 \mathrm{~cm}$ de diámetro y pueden ser pocos o numerosos. La forma miliar consiste en numerosos nódulos menores a $2 \mathrm{~mm}$ de diámetro, distribuidos en forma uniforme. En la forma difusa el órgano está agrandado uniformemente, ligeramente gris y usualmente muy friable (Payne y Fadly, 1997). Microscópicamente los tumores están formados por grandes células linfoides, con una membrana citoplasmática pobremente definida, núcleo vesicular y condensación de la cromatina y uno o más nucléolos acidofílicos notorios.

Tradicionalmente, la EM y la LL se han diagnosticado asociando criterios clínicos y cambios macro y/o microscópicos. En este contexto, el criterio clínico de la edad de la infección, los órganos y el tipo de lesión tumoral observada, son utilizados como criterios de tamices iniciales en el diagnóstico de tumores linfoides. La presencia de una población linfocitaria de diferente tamaño y maduración (pleomórfica) y su forma de infiltración difusa, son criterios para el diagnóstico de la EM. En cambio, el diagnóstico de la LL se basa en la presencia de una población de linfoblastos grandes y homogéneos (monomórficos) agrupados formando folículos (Neumann y Witter, 1979; Randall, 1990; Torriani, 1997).

Estos criterios diferenciales son muchas veces insuficientes y causante de frustración entre los especialistas, sobre todo cuando los tumores linfoides de diferente etiología, infectan los mismos órganos viscerales y/o comprometen a aves en un mismo periodo de edad. Esto se ve agravado con la posibilidad de producirse coinfecciones virales, desencadenando infiltraciones neoplásicas que muchas veces imposibilita una adecuada caracterización microscópica.

Estas dificultades diagnósticas pueden superarse gracias a la prueba de inmunofluorescencia directa utilizando anticuerpos monoclonales (AcMo) específicos para los linfocitos B y T aviares. Su aplicación se fundamenta en que el virus productor de la EM infecta y transforma en un $90 \%$ a linfocitos T mientras que el virus de la LL lo hacen en similar proporción a los linfocitos B (Fadly, 1997). En tal razón, el presente estudio reporta el diagnóstico diferencial en 40 aves con tumores linfoides, en el que además de los criterios clinicos, macro y microscópicos, se utilizó AcMo para los linfocitos T y B para establecer un diagnóstico más preciso de los tumores linfoides aviares. 


\section{Materiales y Métodos}

\section{Lugar de estudio}

La necropsia de gallinas ponedoras se realizó en el Laboratorio de Patología Aviar de la Facultad de Medicina Veterinaria de la Universidad Nacional Mayor de San Marcos (UNMSM) en Lima (Perú), y en las mismas granjas. Las aves procedieron de granjas de las ciudades de Trujillo, Chincha y Lima. El trabajo de histopatología y la prueba de inmunofluorescencia se llevó a cabo en los laboratorios de Histopatología y Virología de la Facultad de Medicina Veterinaria de la UNMSM.

\section{Examen de necropsia y toma de muestras}

Las necropsias de las aves muertas y las sacrificadas por sospechas de presentar enfermedad tumoral, se realizaron siguiendo la técnica convencional (Perusquia, 1985). Las muestras para análisis histopatológicos procedieron de órganos que macroscópicamente presentaban formaciones tumorales (órganos agrandados, con decoloración grisácea difusa o formaciones nodulares en el parénquima del hígado, bazo, corazón o riñones; o con alteraciones morfológicas en el tamaño y color, tales como engrosamiento del proven-trículo o intestino, agrandamiento del ovario en forma de coliflor, bursa aumentada o atrófica, así como agrandamiento de los pulmones o páncreas (Perusquia, 1985; Inga, 1991; Calnek y Witter, 1997).

\section{Histopatología}

Las muestras conservadas en formalina al $10 \%$ fueron sometidas al proceso histológico empleando la coloración hematoxilina/eosina. Los cambios citológicos compatibles con LL están referidos a la homogeneidad de las células tumorales con presencia de mitosis, atipia celular, presencia de linfocitos grandes (linfoblastos) y uniformes (homogéneos). Los linfoblastos presentan una membrana citoplasmática pobremente definida, mucho citoplasma basofílico y un núcleo vesicular prominente en el cual hay marginación y condensación de la cromatina, y uno o más nucléolos acidofílicos.

Los cambios asociados a EM corresponden a presencia de células atípicas y pleomorfismo linfocitario (variación en tamaño y maduración de los linfoblastos de pequeños a medianos). La proliferación es en forma difusa con figuras mitóticas ("célula de Marek”), característica patognomónica. Estos linfocitos transformados son grandes $\mathrm{y}$, en muchos casos, están en proceso de muerte celular con evidencias de cariorrexis y cariólisis.

\section{Inmunofluorescencia (IF)}

Las muestras para la prueba de IF fueron cortadas con el micrótomo de congelación. Los tejidos tumorales fueron sometidos al proceso de congelamiento antes y durante el proceso de corte para obtener tejidos de 4 micras de espesor. Cada pieza de tejido congelado fue depositada en una lámina portaobjetos $\mathrm{y}$, posteriormente, fijada en acetona refrigerada por 15' y guardada en congelación antes de ser sometido a la prueba de IF. En cada corte de tejido se aplicó el anticuerpo monoclonal respectivo marcado con fluoresceína (Southern Biotechnology Associates, Inc. USA). Para la identificación de los linfocitos $\mathrm{B}$, el anticuerpo monoclonal (anti Ig M) se diluyó con PBS, en una proporción de 1:100 para obtener una concentración de $5 \mu \mathrm{g} / \mathrm{ml}$. Para los linfocitos T, el anticuerpo monoclonal (anti CD3) se diluyó con PBS en una proporción de 1:50 para obtener una concentración de $10 \mu \mathrm{g} / \mathrm{ml}$. Los conjugados respectivos se agregaron al tejido y fueron incubados en estufa a $37^{\circ} \mathrm{C}$ por 35 ' (en cámara húmeda). Terminada la incubación, las muestras fueron lavadas con PBS y cubiertas con glicerina. Las muestras fueron observadas en el microscopio de fluorescencia buscando la distribución del marcador en la superficie de las células tumorales. 
La muestra se consideraba positiva a linfocitos B (LL), cuando al aplicar el conjugado anti-Ig M, se notaba el color amarillo verdoso formando masas que correspondían a las células tumorales. La positividad a linfocitos T (MD) se determinaba cuando al aplicar el conjugado anti-CD3, se apreciaba el color amarillo verdoso correspondiente.

\section{Análisis estadístico}

Los cambios macroscópicos observados fueron comparados con los hallazgos de los exámenes histopatológicos y con los resultados de la prueba de IF directa. El grado de concordancia entre los resultados del examen histopatológico y de inmunofluorescencia fue utilizado para determinar si uno de los exámenes es excluyente mediante la prueba de Kappa y Mc Nemar.

\section{Resultados}

\section{Examen de necropsia}

En el examen de necropsia se detectaron tumores en el hígado (Fig.1), bazo, proventrículo, corazón, ovarios, riñones, pulmones, mesenterio, intestino, nervio, bursa, páncreas, timo, piel y músculo. El hígado, el bazo y el proventrículo fueron los órganos afectados con mayor frecuencia $(67.5,52.5$ y $47.5 \%$, respectivamente . Cuadro 1). La piel, el músculo esquelético y el timo fueron los órganos menos afectados. Las alteraciones macroscópicas produjeron una evidente pérdida de la arquitectura normal de los tejidos afectados. Los tumores en ovario mostraban una apariencia de coliflor, el proventrículo se encontraba generalmente engrosado y la bursa presentaba tumores de tipo nodular o engrosamiento difuso.

Una gallina llegó a presentar ocho órganos con tumores (hígado, bazo, corazón, proventrículo, riñones, pulmones, nervio y ovario). Dentro de las aves afectadas, 27/40 presentaron entre 2-4 órganos afectados, 7/ 40 entre 5-8 órganos comprometidos y 6/40 con un solo órgano afectado (Cuadro 2).
El hígado, que fue el órgano afectado con mayor frecuencia, se encontraba agrandado ocupando gran parte de la región abdominal y con zonas de color más claro de lo normal. Cuando el bazo estaba comprometido se encontraba aumentado de tamaño en forma homogénea.

El examen de necropsia determinó que 24/40 aves examinadas tenían lesiones compatibles con la enfermedad de Marek y las restantes (16/40) con lesiones compatibles con leucosis linfoide (Cuadro 3). El engrosamiento de los nervios, tumores en proventrículo y el carácter difuso del proceso fueron evidencias patológicas sugerentes de la GM. Los tumores de tipo nodular afectando a la bursa, hígado y bazo fueron los aspectos macroscópicos considerados para arribar a un posible diagnóstico de LL.

\section{Histopatología}

El 75\% (18/24) de las aves diagnosticadas macroscópicamente como EM tenían infiltraciones linfoides pleomórficas compatibles histológicamente con EM, en tanto que las otras (6/24) poseían cambios histológicos monomórficos compatibles con LL. Todas las aves diagnosticadas macroscópicamente como LL (16/40) presentaron evidencias histológicas correspondientes a LL.

En el grupo de aves con cambios histológicos compatibles con EM se observaron las lesiones intestinales caracterizadas por infiltración difusa de poblaciones pleomórficas de linfocitos con figuras mitóticas en todas las capas del intestino (Fig. 2). El nervio ciático engrosado estuvo repleto de células tumorales que distorsionan su estructura y desplazan las neuronas (Fig. 3). En el bazo, la infiltración alteraba los folículos esplénicos y en el páncreas se produjo disociación de los acinos (figs. 4 y 5).

La estructura histológica es diferente en el caso de LL. Las lesiones son focales con presencia de linfocitos grandes uniformes (homogéneos), encontrándose en la misma 
etapa de desarrollo primitivo y referidos como linfoblastos de la leucosis aviar. En el hígado, los tumores fueron multifocales con desplazamiento y/o compresión de los hepatocitos a causa del crecimiento expansivo de los focos tumorales (Fig. 6). En el ovario con apariencia microscópica de coliflor, se aprecia gran cantidad de células tumorales monomórficas alrededor de los folículos ováricos (figs. 7 y 8). Las células tumorales comprimen las células parenquimatosas del órgano afectado, no se infiltran entre ellas, tienen una membrana citoplasmática pobremente definida, mucho citoplasma basofílico y un núcleo vesicular en el cual hay marginación y condensación de la cromatina y presencia de uno o más nucleolos acidofílicos .

En algunas láminas se observaron además del patrón característico, grupos de células identificadas como mielocitos, presentes mayormente en hígado y ovarios, sugeriendo la presencia de una infección mixta y generalmente con la enfermedad de Marek.

\section{Inmunofluorescencia}

Nueve de los 18 (50\%) tumores clasificados por histopatología como enfermedad de Marek, fueron positivos al marcador CD3 (células T) en la prueba de inmunofluorescencia (Cuadro 4). De estos 9 positivos, 6/9 solamente fueron positivos para el CD3 y 3/9 a ambos marcadores CD3 (células T) e IgM (células B). En los 9/18 restantes se logró observar que 8/9 fueron negativos a ambos marcadores CD3 e IgM, y en 1/9 resultó positivo para IgM (LL). Similarmente, en 12/22 (54.6\%) diagnosticados por histopatología como leucosis linfoide, se identificaron marcadores de células B (IgM+). Seis de estas aves fueron solamente positivos a IgM y las otras seis presentaron marcadores para ambos tipos de células. En el resto (10/22) con cambios histologicos indicadores de LL, 6/10 fueron positivos a marcadores CD3 (células T) y los 4 restantes negativos para ambos marcadores (Cuadro 4).
La prueba de inmunofluorescencia permitió la detección más precisa del tipo de tumor involucrado. La utilización de esta prueba determinó que 12/40 (30\%) animales con tumores tenían marcadores CD3 (Enfermedad de Marek), 7/40 (17.5\%) eran positivos a IgM (Leucosis Linfoide), 9/40 (22.5\%) tenían ambos marcadores de células T y B (infecciones mixtas) y los restantes 12/40 (30\%) fueron negativos para ambos marcadores (Cuadro 4).

Todos los casos (4/4) en los que macroscópicamente estuvo involucrado el nervio resultaron positivos a CD3, corroborando que estas alteraciones son típicas de EM. Con excepción de los tumores detectados en la piel y el músculo (negativos a ambos marcadores ), todo el resto de órganos comprometidos reaccionaron a los 2 marcadores. Más del 50\% de las lesiones encontradas en los intestinos, bursa y proventrículos fueron positivos a marcadores de células $\mathrm{T}$ en tanto que más del $50 \%$ de las lesiones encontradas en el mesenterio, páncreas y ovarios fueron positivos al marcador de las células $\mathrm{B}$. El único tumor detectado en el timo resultó positivo para ambos marcadores de células $\mathrm{T}$ y B (Cuadro 5). En total, 7/27 lesiones hepáticas, 7/13 cardiacas, 2/6 pulmonares, 2/8 renales, 1/21 esplénicas, 1/9 ováricas y 1/19 proventriculares resultaron negativas para ambos marcadores.

Las pruebas de Kappa y Mc Nemar mostraron que para la enfermedad de Marek, el grado de concordancia entre histopatología e inmunofluorescencia es de -0.045 ( $p>0.05$ ); y para leucosis linfoide el grado de concordancia entre ambas pruebas (HP e IF) es de 0.314 ( $p>0.05$ ), por lo que se deduce que ambos métodos de diagnóstico no son mutuamente reemplazables.

\section{Discusión}

Los tumores linfoides aviares ocasionados por agentes virales son gene ralmente 


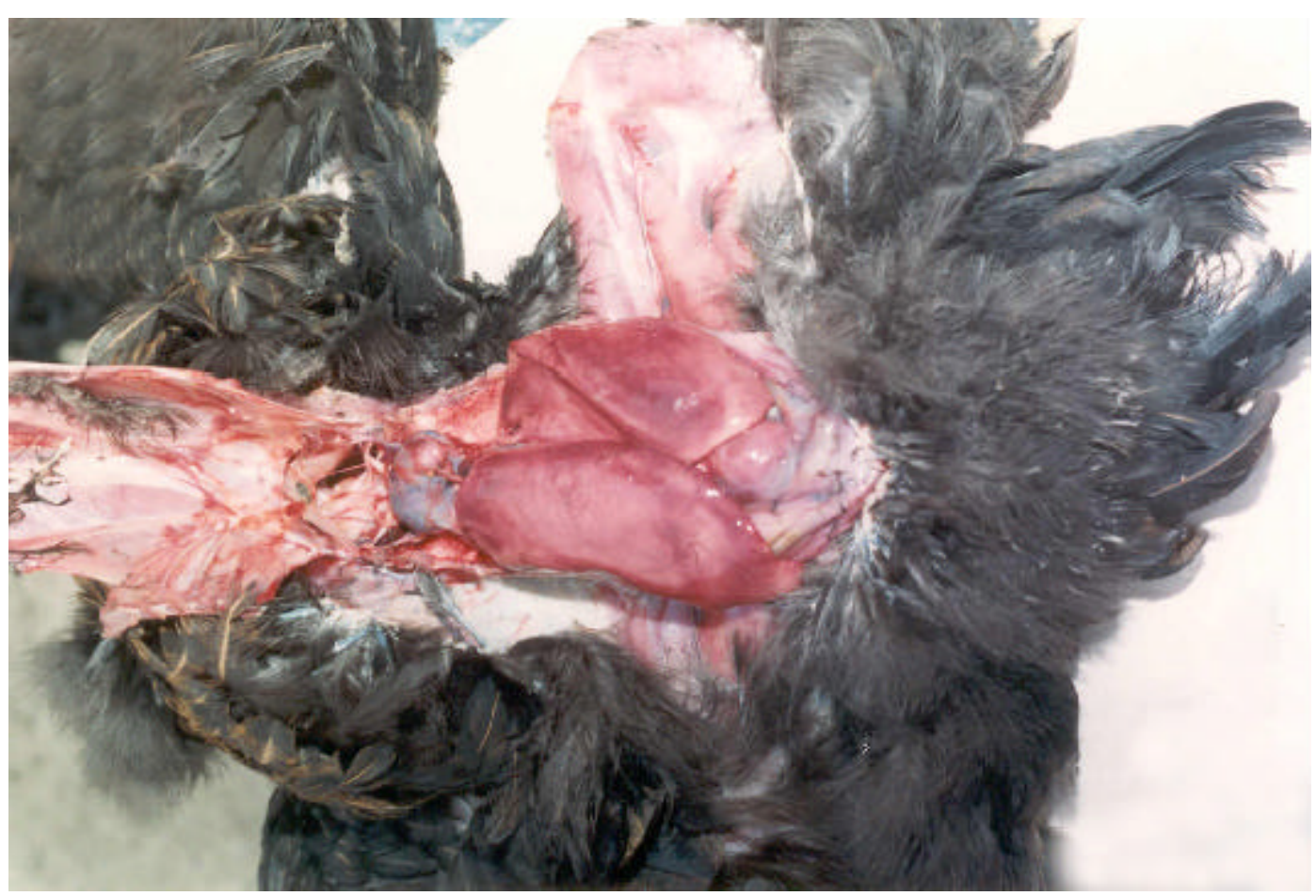

Figura 1. Hígado aumentado de tamaño en una gallina con tumores linfoides

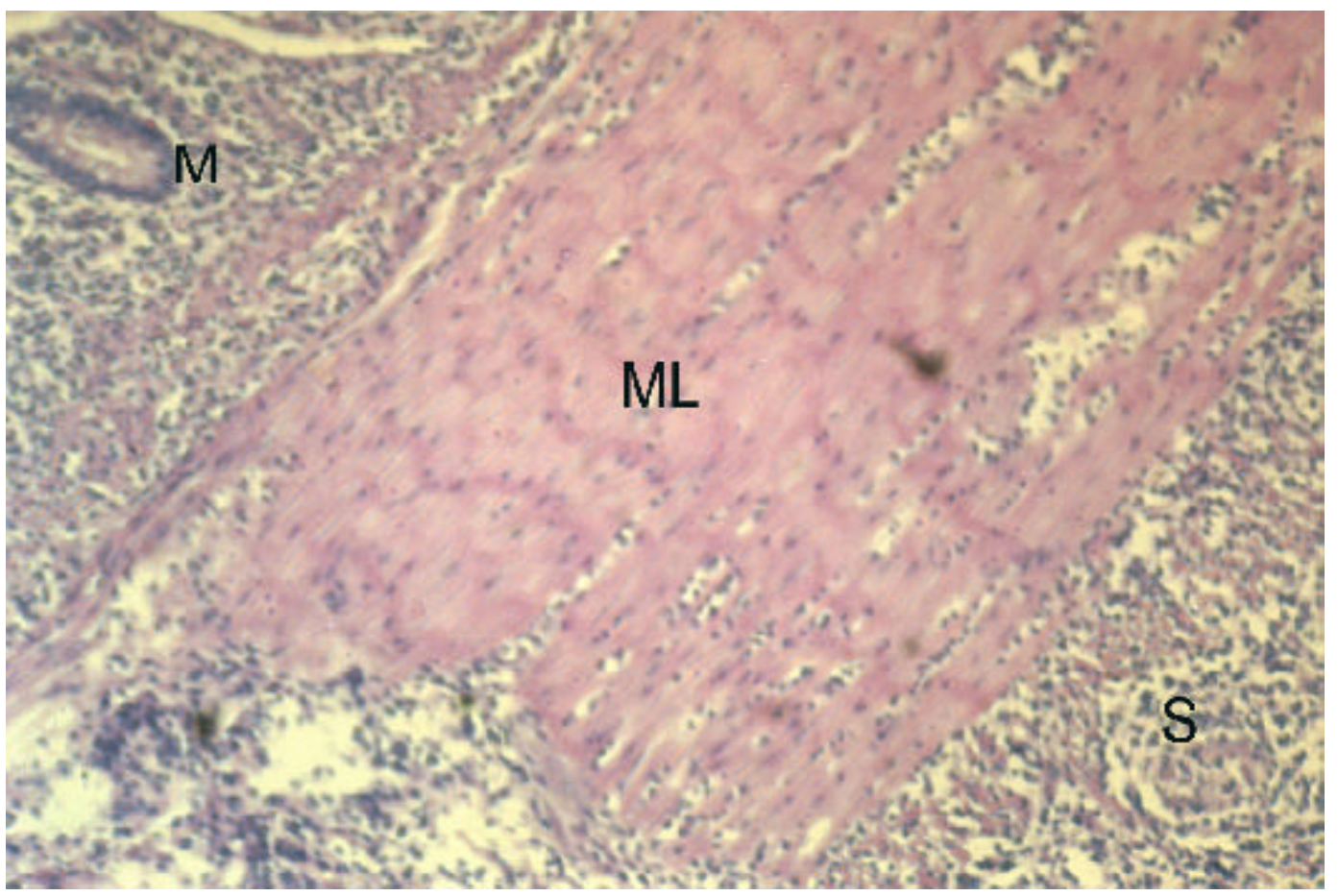

Figura 2. Intestino delgado con infiltración difusa de células tumorales afectando capa mucosa (M) músculo liso (ML) y serosa (S) en la enfermedad de Marek. 10X 


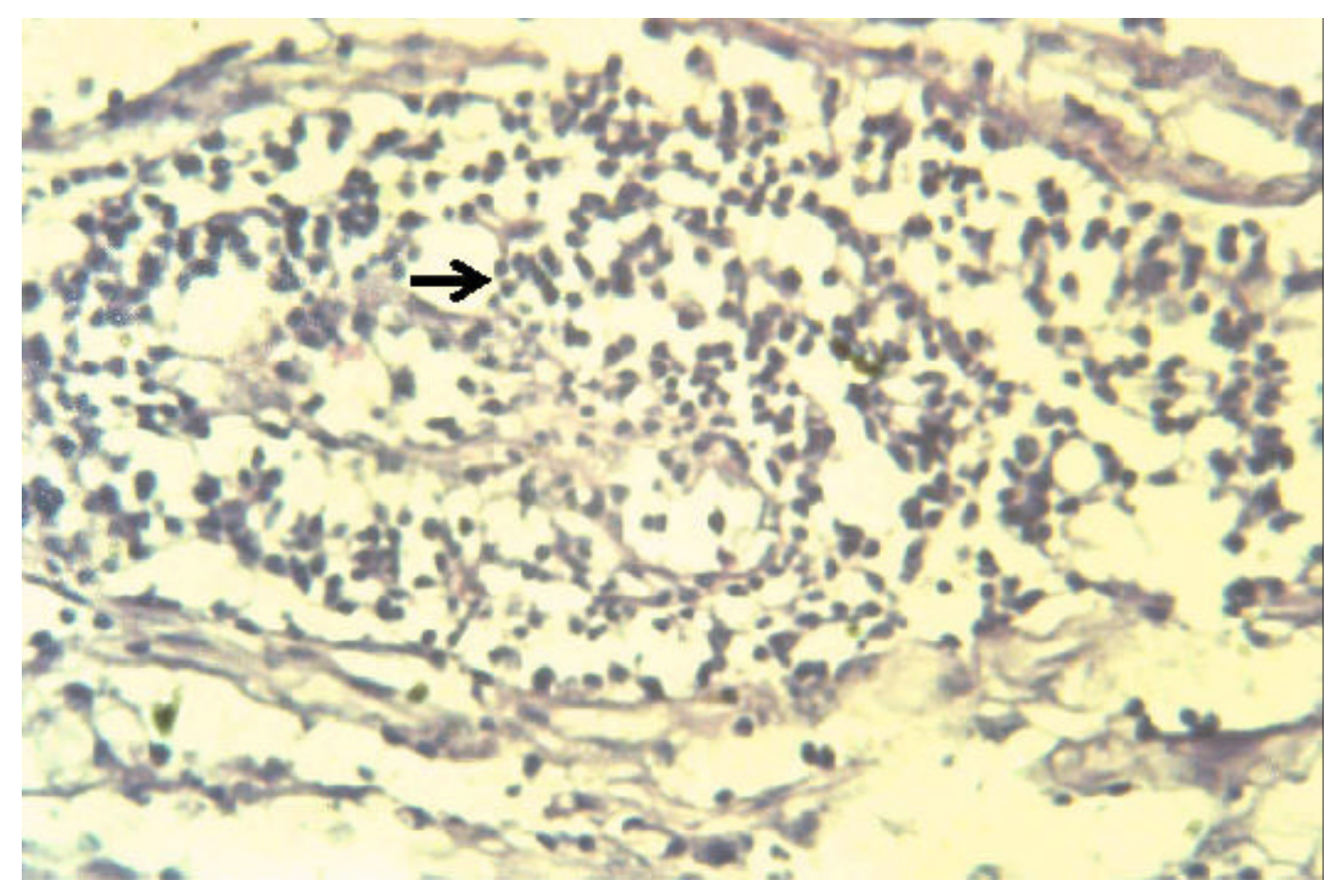

Figura 3. Nervio ciático con infiltración difusa tumoral de células pleomórficas (flecha) en la enfermedad de Marek. 25X

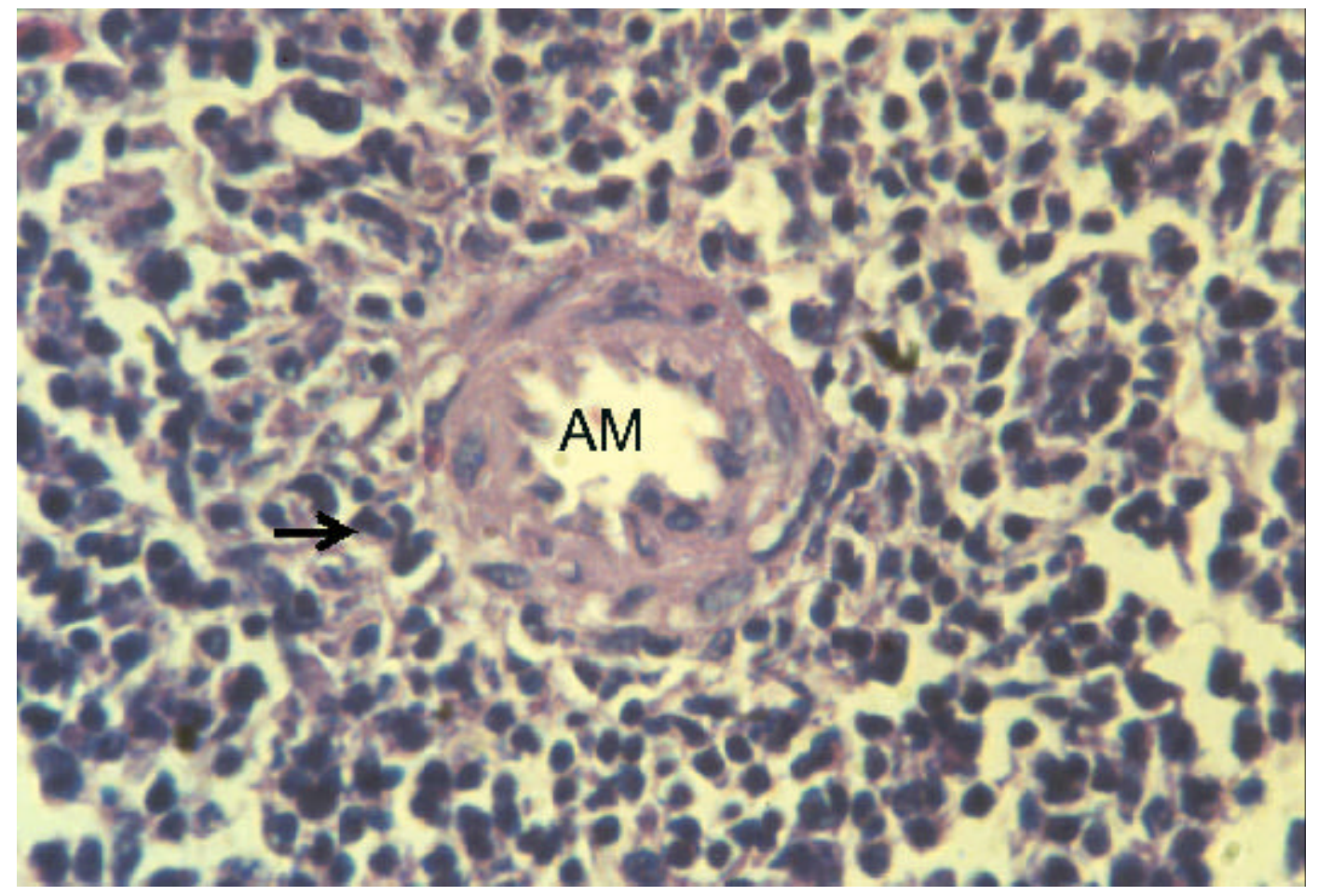

Figura 4. Bazo con infiltración periarteriolar de células tumorales pleomórficas en la enfermedad de Marek. Arteriola de Maipighi (AM), células tumorales (flecha) 


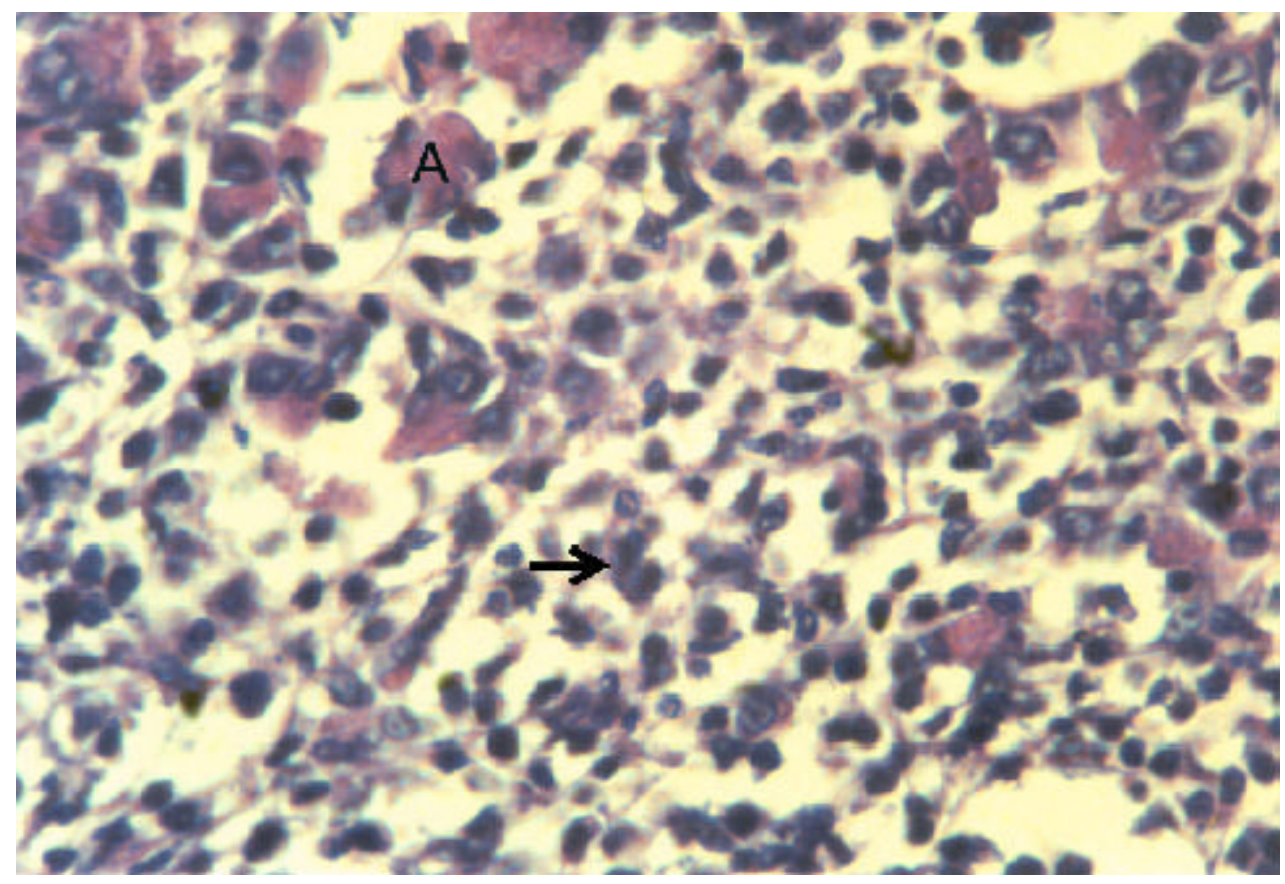

Figura 5. Páncreas con infiltración tumoral difusa de células pleomórficas (flecha) con disociación acinar (A) en la enfermedad de Marex. 40X

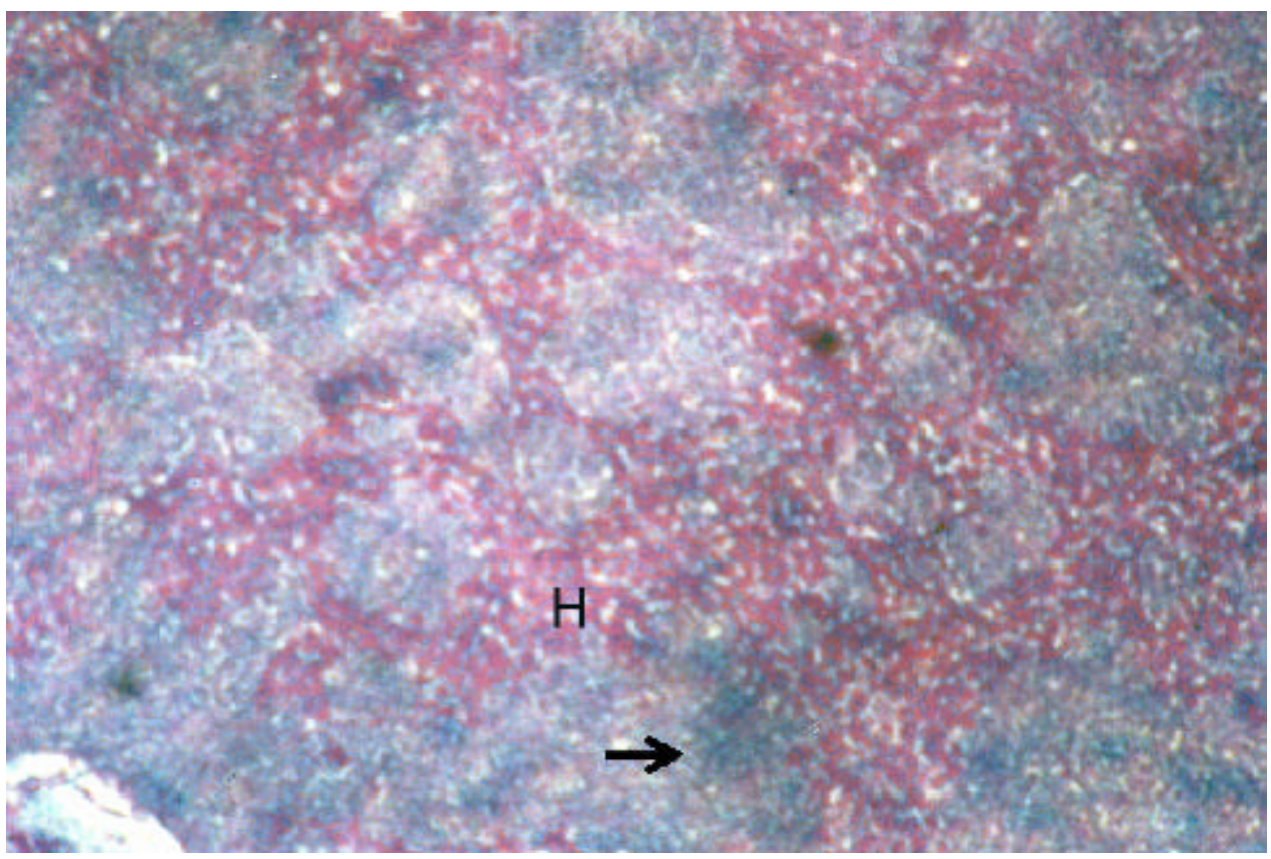

Figura 6. Hígado con infiltración multifocal por células tumorales (flecha) de crecimiento expansivo en la leucosis linfoide. Hepatocitos $(H) .4 X$ 


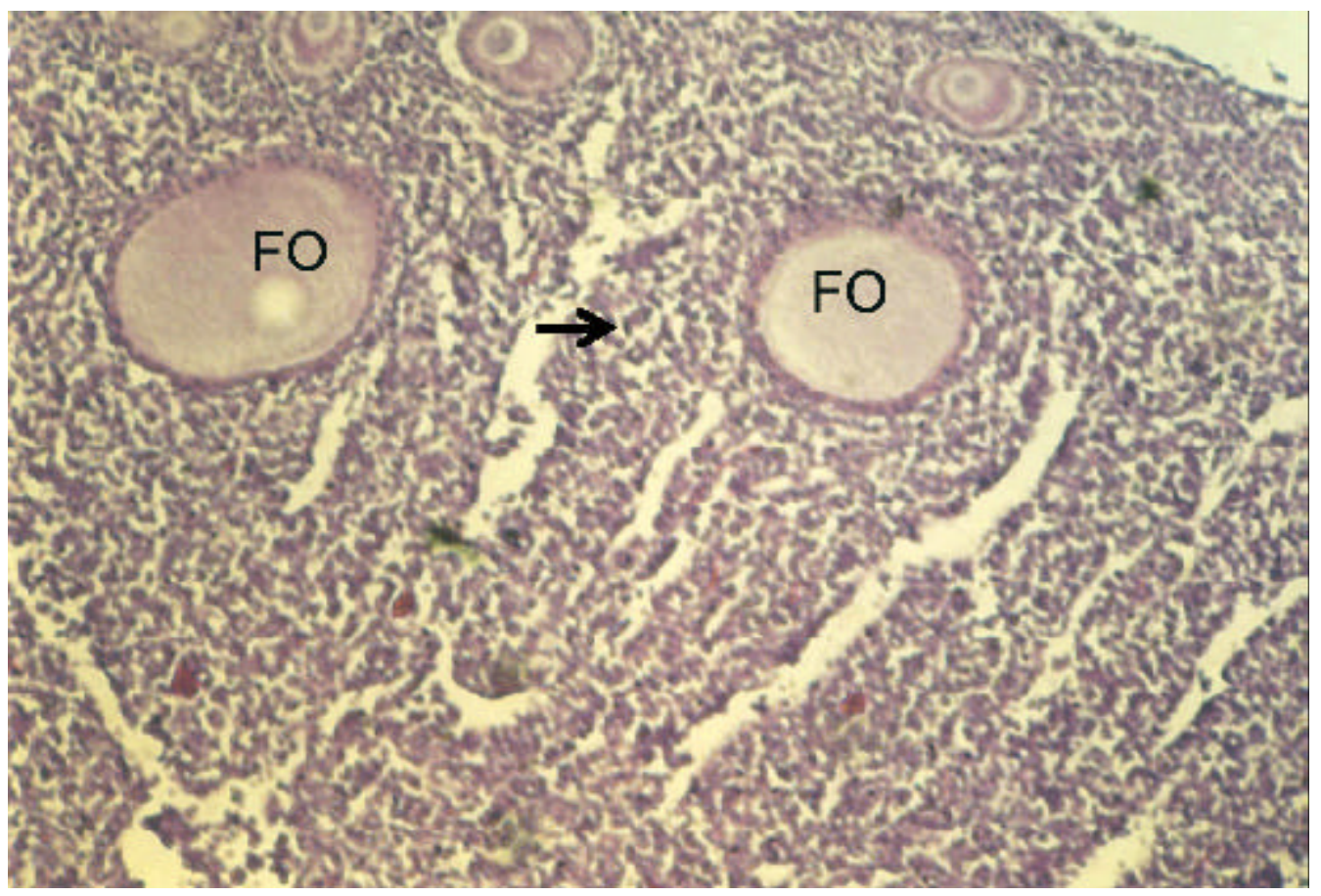

Figura 7. Ovario con amplia proliferación de células tumorales monomórficas de tipo linfobásticas perifolicular (flecha) Folículos ováricos (FO). 10X

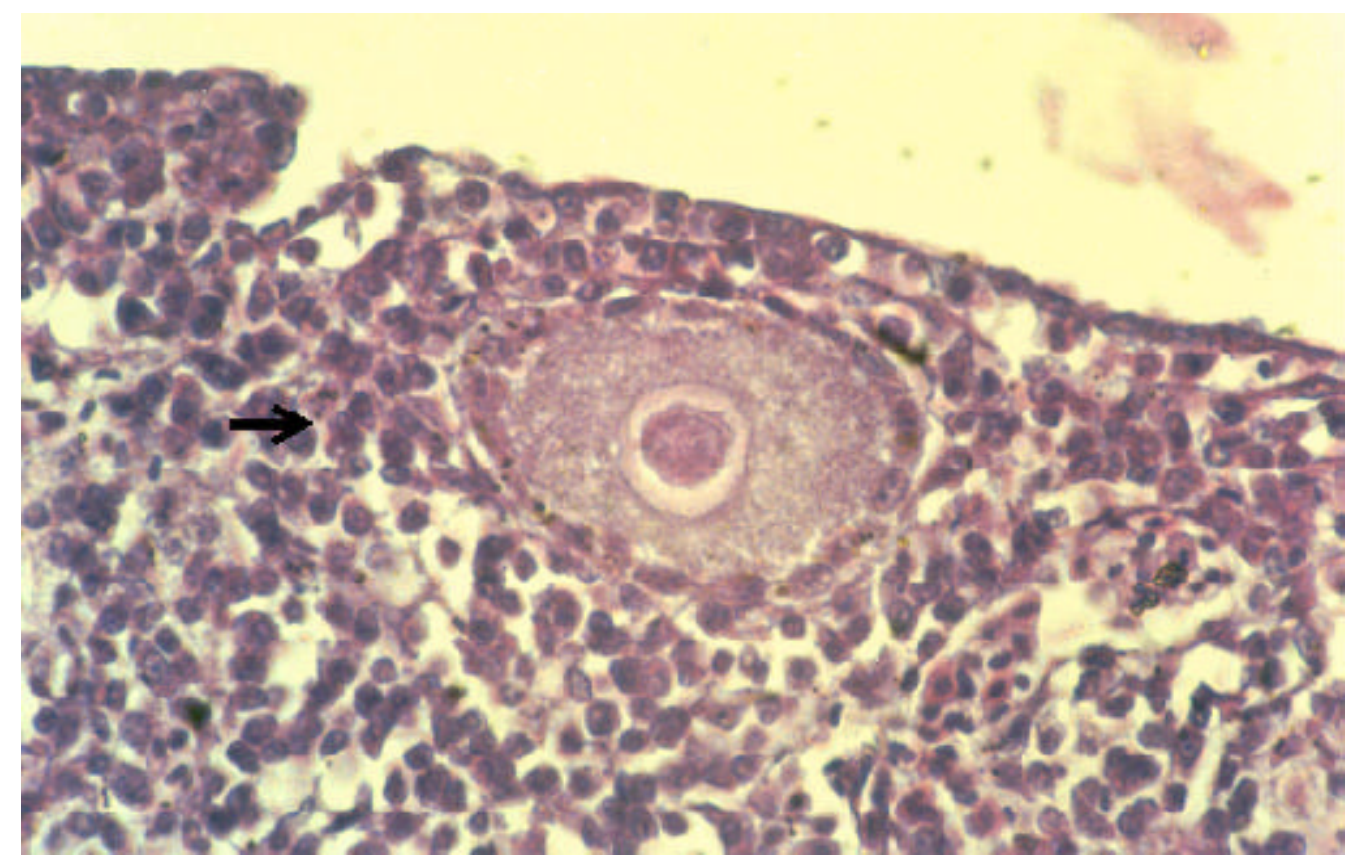

Figura 8. Ovario tumoral del ave de la Fig. 7. Folículo ovárico rodeado de abundantes células tumorales monomórficas de tipo linfoblásticas (flecha) en la leucosis linfoide. 45X 
Cuadro 1. Cuantificación de los órganos afectados con tumores linfoides (enfermedad de Marek o leucosis linfoide) observados a la necropsia $(n=40)$ en gallinas ponedoras de granjas comerciales de tres ciudades de Lima

\begin{tabular}{lrr}
\hline & \multicolumn{2}{c}{ Gallinas ponedoras } \\
\cline { 2 - 3 } Órgano afectado & $\mathrm{n}$ & $(\%)$ \\
\hline Timo & 1 & 2.5 \\
Intestino delgado & 4 & 10.0 \\
Nervios & 4 & 10.0 \\
Piel & 1 & 2.5 \\
Bursa de Fabricio & 3 & 7.5 \\
Hígado & 27 & 67.5 \\
Bazo & 21 & 52.5 \\
Músculo esquelético & 1 & 2.5 \\
Corazón & 13 & 32.5 \\
Proventrículo & 19 & 47.5 \\
Riñones & 8 & 20.0 \\
Mesenterio & 5 & 12.5 \\
Pulmones & 6 & 15.0 \\
Ovarios & 9 & 22.5 \\
Páncreas & 3 & 7.5 \\
\hline
\end{tabular}

Cuadro 2. Número de órganos afectados por ave con tumores linfoides, compatibles con enfermedad de Marek o leucosis linfoide, observados a la necropsia en gallinas ponedoras $(n=40)$ de granjas comerciales en tres ciudades de Lima

\begin{tabular}{lcccccccc}
\hline & \multicolumn{7}{c}{$\mathrm{N}^{\circ}$ de órganos afectados } \\
\cline { 2 - 9 } & 1 & 2 & 3 & 4 & 5 & 6 & 7 & 8 \\
\hline Aves afectadas (n) & 6 & 11 & 8 & 8 & 3 & 3 & 0 & 1 \\
Aves afectadas (\%) & 15.0 & 27.5 & 20.0 & 20.0 & 7.5 & 7.5 & 0.0 & 2.5 \\
\hline
\end{tabular}

Cuadro 3. Resultados comparativos entre alteraciones macroscópicas a la necropsia y prueba de inmunofluorescencia

\begin{tabular}{|c|c|c|c|c|c|c|}
\hline \multirow{3}{*}{ Prueba de Inmunofluorescencia } & \multicolumn{4}{|c|}{ Resultados de la Necropsia } & \multirow{2}{*}{\multicolumn{2}{|c|}{ Total }} \\
\hline & \multicolumn{2}{|c|}{ Enf. de Marek } & \multicolumn{2}{|c|}{ Leucosis linfoide } & & \\
\hline & $\mathrm{n}$ & $\%$ & $\mathrm{n}$ & $\%$ & $\mathrm{n}$ & $\%$ \\
\hline CD3 positivo (EM) & 8 & 33.3 & 4 & 25.0 & 12 & 30.0 \\
\hline IgM positivo (LL) & 4 & 16.7 & 3 & 18.8 & 7 & 17.5 \\
\hline $\begin{array}{l}\text { CD3 e IgM positivos } \\
\text { (infecciones mixtas) }\end{array}$ & 6 & 25.0 & 3 & 18.8 & 9 & 22.5 \\
\hline CD3 e IgM negativos & 6 & 25.0 & 6 & 37.5 & 12 & 30.0 \\
\hline Total & 24 & 100.0 & 16 & 100.0 & 40 & 100.0 \\
\hline
\end{tabular}


Cuadro 4. Resultados comparativos entre alteraciones histopatológicas y prueba de inmunofluorescencia

\begin{tabular}{|c|c|c|c|c|c|c|}
\hline \multirow{3}{*}{ Prueba de inmuofluorescencia } & \multicolumn{4}{|c|}{ Diagnóstico por histopatología } & \multirow{2}{*}{\multicolumn{2}{|c|}{ Total }} \\
\hline & \multicolumn{2}{|c|}{$\begin{array}{l}\text { Enfermedad de } \\
\text { Marek }\end{array}$} & \multicolumn{2}{|c|}{$\begin{array}{l}\text { Leucosis } \\
\text { linfoide }\end{array}$} & & \\
\hline & $\mathrm{n}$ & $\%$ & $\mathrm{n}$ & $\%$ & $\mathrm{n}$ & $\%$ \\
\hline CD3 positivo (EM) & 6 & 33.3 & 6 & 27.3 & 12 & 30.0 \\
\hline IgM positivo (LL) & 1 & 5.6 & 6 & 27.3 & 7 & 17.5 \\
\hline $\begin{array}{l}\text { CD3 e IgM positivos } \\
\text { (infecciones mixtas) }\end{array}$ & 3 & 16.7 & 6 & 27.3 & 9 & 22.5 \\
\hline CD e IgM negativos & 8 & 44.4 & 4 & 18.2 & 12 & 30.0 \\
\hline Total & 18 & 100.0 & 22 & 100.0 & 40 & 100.0 \\
\hline
\end{tabular}

Cuadro 5. Asociación entre lesiones macroscópicas características de la Enfermedad de Marek y de la Leucosis Linfoide, y presencia de marcadores de células T y B

\begin{tabular}{|c|c|c|c|c|c|}
\hline \multirow[t]{2}{*}{ Órgano } & \multirow{2}{*}{$\begin{array}{l}\text { Total de } \\
\text { muestras }\end{array}$} & \multicolumn{2}{|c|}{ Marcador de células T } & \multicolumn{2}{|c|}{ Marcador de células B } \\
\hline & & $\mathrm{n}$ & $\%$ & $\mathrm{n}$ & $\%$ \\
\hline Nervio & 4 & 4 & 100.0 & 0 & 0.0 \\
\hline Piel & 1 & 0 & 0.0 & 0 & 0.0 \\
\hline Proventrículo & 19 & 10 & 52.6 & 8 & 42.1 \\
\hline Corazón & 13 & 5 & 38.4 & 3 & 23.0 \\
\hline Bursa & 3 & 2 & 66.6 & 1 & 33.3 \\
\hline Ovarios & 9 & 3 & 33.3 & 5 & 55.5 \\
\hline Riñones & 8 & 3 & 37.5 & 3 & 37.5 \\
\hline Intestino & 4 & 3 & 75.0 & 2 & 50.0 \\
\hline Mesenterio & 5 & 1 & 20.0 & 4 & 80.0 \\
\hline Páncreas & 3 & 1 & 33.3 & 2 & 66.6 \\
\hline Pulmones & 6 & 2 & 33.3 & 2 & 33.3 \\
\hline Músculo & 1 & 0 & 0.0 & 0 & 0.0 \\
\hline Timo & 1 & 1 & 100.0 & 1 & 100.0 \\
\hline Hígado & 27 & 12 & 44.4 & 8 & 29.6 \\
\hline Bazo & 21 & 12 & 57.1 & 8 & 38.0 \\
\hline
\end{tabular}


producto de infecciones retrovirales del grupo de la LL y el herpesvirus responsable de la EM. Estos tumores linfoides, en forma microscópica son generalmente indistinguibles dificultando su diagnóstico definitivo. El diagnóstico diferencial usualmente depende de las observaciones de cambios histopatológicos asociados con la historia clínica, signos macroscópicos y ciertas características citológicas. La histiogénesis producto de estas infecciones indica que el agente retroviral de la LL transforma usualmente a células B y la infección herpética a las células T. Estas evidencias han permitido utilizar AcMo dirigidos a antígenos (marcadores) celulares para identificar a los linfocitos B (IgM+) o células $\mathrm{T}$ (CD3+). Estos AcMo conjugados con isotiocianato de fluoresceína se utilizaron en el presente estudio mediante pruebas de immnunofluorescencia (IF) directa para la diferenciación de tumores linfoides aviares asociados con LL y EM.

El análisis histopatológico fue utilizado para agrupar ciertos cambios celulares descritos como pleomorfismo linfocítico con presencia de mitosis, cariorrexis y/o cariolisis dentro de los patrones asociados con la EM y la presencia de linfoblastos homogéneos como características histológicas de LL. Con estos criterios se clasificó al $45 \%$ de los tumores como lesiones compatibles como EM y el 55\% restante dentro de la denominada LL. Este criterio histopatológico fue utilizado para ser contrastado con la presencia de marcadores celulares mediante los AcMo y poder diferenciar a los linfocitos B de las células T. En algunos casos la presencia de células compatibles con mielocitos infiltrando los órganos, fueron tomados como una posible infección o superinfección del virus de la leucosis tipo J (Hihara et al., 1998; Fadly, 1999; Zavala, 2000).

Los resultados de la prueba de IF confirman la dificultad en el diagnóstico definitivo de las causas de los tumores linfoides en las aves. Por un lado, se confirma que la histopatología es una herramienta adicional muy importante en el diagnóstico del tipo de neoplasia linfoide en órganos tumorales, pero fundamentalmente se deberá tener en cuenta el principal órgano blanco transformado, como nervios en la EM y bursa en LL (Julian, 1998; Payne y Mc Kay, 1999). En este estudio, los 4/40 casos en los que los nervios estuvieron involucrados resultaron ser histológicamente e IF positivos a la EM. Esto, sin embargo, no lo fue para casos sospechosos de LL (1/3 de casos en los que la bursa estuvo involucrada, la IF fue positiva a linfocitos B y el resto dio positivo a linfocitos T). Esto es contrario a lo expresado por varios autores que indican que la lesión de la bursa es patognomónica de leucosis linfoide (Fadly, 1997; Payne y Mc Kay, 1999), pero sin lugar a dudas, refuerza el concepto de la habilidad en la lectura e interpretación de los cambios citológicos. La bursa puede ser tomada por células tumorales de origen B (LL) y células $\mathrm{T}$ (EM), y la diferenciación depende del tipo de infiltración tumoral. Se menciona que LL infiltra focal o nodularmente, mientras que EM lo hace interfolicularmente comprometiendo además a la plica bursal.

El análisis estadístico indica que para LL, existe una concordancia regular entre la histopatología e IF, mientras que para la EM hay una pobre concordancia entre los dos parámetros. Esto se explica porque microscópicamente, es posible una identificación más precisa de poblaciones celulares homogéneas de leucosis linfoide concordando con el resultado de IF, a diferencia de la difícil identificación microscópica de las células pleomórficas de la enfermedad de Marek.

Las dificultades diagnósticas de tumores linfoides en aves radica en la habilidad de ambos agentes virales de comprometer a más de un órgano anatómico. Las neoplasias asociadas a LL y la EM suelen ocurrir en los mismos órganos viscerales y aún durante el mismo periodo de edad. Esta dualidad infectiva ha podido ser identificada en el estudio, ya que con excepción de lesiones encontradas en piel y músculo (negativos a ambos marcadores), todos los órganos fue- 
ron positivos a uno o a ambos marcadores analizados (Cuadro 5). Las habilidades virales de infectar un mismo órgano refuerza la necesidad de realizar exámenes microscópicos; sin embargo, esto no es definitivo, pues muchas veces un acertado diagnóstico dependerá de la habilidad en la lectura de los cambios histopatológicos y sobre todo de encontrar las características apropiadas en las células tumorales involucradas (Wakenell, 1997; Payne y Mc Kay, 1999). Por estas razones, la prueba de IF representa una alternativa viable para el diagnóstico diferencial ya que tiene la capacidad de distinguir entre linfomas de células $\mathrm{B}$ y $\mathrm{T}$, debido a que utiliza anticuerpos monoclonales específicos para antígenos de superficie celular de linfocitos T y B (Jeurissen et al., 2000).

Si bien es cierto que la prueba de la identificación de marcadores celulares para los linfocitos B y T son de ayuda en el diagnóstico diferencial de los tumores linfoides en aves, estos deben ser aceptados como herramientas adicionales en el diagnóstico, pues el retrovirus causante de LL transforma fundamentalmente a los linfocitos B. En este concepto, el tumor con cambios histopatológicos altamente compatibles con EM y positivos a células B no deben ser totalmente descartados como EM (Cuadro 4). En todos estos casos sería necesario implementar herramientas moleculares a fin de precisar o descartar la presencia de un determinado agente viral.

Doce de las 40 (30\%) lesiones tumorales evidenciaron infecciones mixtas. El mayor porcentaje de estos casos (8/12) correspondieron a casos que histopatológicamente fueron clasificados como EM (Cuadro 4). Estos resultados refuerzan las evidencias sobre infecciones concurrentes entre el virus de la leucosis aviar y cepas muy virulentas del virus de la EM en el desarrollo de tumores más intensos que cuando actúan de manera separada (Witter, 1998; Alzamora, 2000; Zavala, 2000). La intensidad de los tumores no ha sido evaluada en el presente estudio pero tampoco descarta esta posibilidad de ocurrencia en nuestro medio. La coexistencia de infecciones virales en lesiones con tumores en nuestro medio se refuerza, además, por la presencia de evidencias histopatológicas (hígado y ovario) de infección del virus de la leucosis aviar del tipo J (Zavala, 1999).

Llama la atención que 12/40 (30\%) de los casos tumorales fueron negativos para ambos marcadores. Esto evidenciaría que estos tumores pueden tener origen no linfoide o los AcMo no fueron capaces de identificar antígenos celulares. Se debe mencionar, además que las lesiones tumorales encontradas en la piel y músculo fueron negativas a los marcadores empleados en el estudio. La negatividad en todos los casos puede deberse a un inadecuado muestreo o la especificidad del anticuerpo monoclonal empleado.

El uso combinado de cambios histopatológicos y la presencia de marcadores de los linfocitos B y T han sido utilizados en el diagnóstico diferencial en 40 casos de linfomas aviares. Los cambios citológicos evidenciaron que 18/40 (45\%) tenían lesiones compatibles con EM y el restante (22/40), cambios correspondientes a LL. Se encontró además que 5/40 (12.5\%) casos tenían infiltraciones celulares mixtas de células linfoides y mielocitos sugiriendo la presencia de infecciones del virus de la LL tipo J. La prueba de IF directa confirmó que el 50\% (9/18) de casos clasificados como EM tenían marcadores de células $\mathrm{T}$ y 12/22 (54.6\%) de los casos agrupados como LL tenían marcadores de linfocitos B. En ambos grupos se encontraron infiltraciones linfoides mixtas, 3/9 (EM) y 6/12 (LL) fueron positivos a ambos marcadores celulares para células B y T. Por otro lado en 12/40 (30\%) casos no se lograron detectar marcador linfoides en las infiltraciones tumorales. Estos resultados sugieren la presencia de más de un retrovirus involucrado en procesos tumorales aviares incluyendo el LL tipo J y probablemente el retrovirus de la reticuloendoteliosis. Sugieren además, que las infecciones mixtas de virus de la LL y el herpesvirus de la EM son más prevalentes de lo sospechado. Las dificulta- 
des diagnósticas de estos tipos de tumores altamente prevalentes en el país muestran la necesidad de implementar pruebas moleculares (PCR) adicionales para arribar a un diagnóstico más preciso.

Agradecimientos: Los autores agradecen a los médicos veterinarios de las diversas granjas que permitieron el muestreo de las aves estudiadas. Agradecen también a los Laboratorios de Patología Aviar y Virología de la FMV, UNMSM, por el apoyo incondicional para la realización de las pruebas utilizadas en el trabajo.

\section{ReFERENCIAS B IBLIOGRÁFiCAS}

1. Calnek, B.W.; R.L. Witter. 1997. Marek's Disease. En: Disease of poultry. $10^{\text {th }}$ ed. B.W. Calnek; H.J. Barnes Saif (eds). Iowa State University Press. Ames, I.A. p 361-413.

2. Fadly, A.M. 1997. Criteria for the differential diagnosis of viral lymphomas of chickens: A review. Avian Tumor Viruses Symposium. 40 ${ }^{\text {th }}$ Annual Meeting AAAP. USA.

3. Fadly, A.M. 1999. Una revisión de la infección y enfermedad producida por el virus de la Leucosis Aviar subgrupo J en pollos de carne. Memorias XVI Congreso Latinoamericano de Avicultura. Lima, Perú. p 75-77.

4. Hihara, H.; K. Imar; K. Tsukamoto; K. Nakamura. 1998. Isolation of serotype 2 Marek's disease virus from a cell line of avian lymphoid leukosis. J. Vet. Med. Sci. 60: 143-148.

5. Inga, E. 1991. Análisis estadístico retrospectivo de las principales enfermedades diagnosticadas en el laboratorio de patología aviar en los últimos 10 años. Tesis de Bachiller. Facultad de Medicina Veterinaria, Universidad Nacional Mayor de San Marcos. Lima, Perú. 52 p.

6. Jeurissen, S.H.; E. Claassen; A.G. Boonstra-Blom; L. Vervelde; E. Marga Jonse. 2000. Immunocytochemical techniques to investigate the pathogenesis of infectious microorganisms and the concurrent immune response of the host. Dev. Comp. Immunol. 24: 141-151.

7. Julian, R.L. 1998. Leukosis/Sarcoma Group. En: Resumen Curso Internacional de Postgrado. Diagnóstico Patológico en Aves. FMV, UNMSM. Lima.

8. Muñoz, R. 2000. Control de Marek. Ind. Avícola. Diciembre. p 22-25.

9. Neumann, U.; R.L. Witter. 1979. Differential diagnosis of lymphoid leucosis and Marek's disease by tumorassociated criteria. I. Studies on experimentally infected chickens. Avian Dis. 23: 417-425.

10.Payne, L.N.; A.M. Fadly. 1997. Leukosis/sarcoma group. En: Disease of Poultry. $10^{\text {th }}$ ed. Calnek, B.W. (ed). Iowa State University. Press Ames, I.A. USA. p 426-456.

11. Payne, L.N.; J.C. Mc Kay. 1999. Diagnóstico diferencial de las leucosis aviares y el linfoma de la enfermedad de Marek y los procedimientos para erradicar los virus exógenos de la leucosis aviar. Memorias XVI Congreso Latinoamericano de Avicultura. Lima. p 68-73.

12. Perusquia, M.T. 1985. Necropsia en aves. EJ. Trillas. México.

13. Randall, W. 1990. Atlas a color de las enfermedades de las aves de corral. Interamericana. México.

14. Spencer, J.L. 1998. Erradicación del virus de la leucosis aviar. Prevención. XXXV Symposium de la WPSA. EXPOAVIGA 98. España. p 33-43.

15. Torriani, J. 1997. Confirmación de leucosis aviar en un lote de reproductoras pesadas. Mundo Avícola \& Porcino 23: 55.

16. Wakenell, P. 1997. An overview of problems in diagnosis of neoplastic diseases of poultry. Avian Tumor Viruses Symposium. 40 ${ }^{\text {th }}$ Annual Meeting. AAAP. USA.

17. Zavala, G. 2000. The status of Avian Leukosis infection in meat-type chickens. Proceedings 2000 Georgia International Poultry Course. Georgia Center for Continuing Education. Univ. of Georgia, GA, USA. 